\title{
Suppression of forest fuel thermal decomposition under the influence of liquid aerosol and water droplets with additives
}

\author{
Nikita Shlegel ${ }^{1}$, Alena Zhdanova ${ }^{1, *}$, Svetlana Kralinova ${ }^{1}$, and Ivan Voytkov ${ }^{1}$ \\ ${ }^{1}$ National Research Tomsk Polytechnic University, 634050 Tomsk, Russia
}

\begin{abstract}
This article presents findings of experimental research into suppressing the thermal decomposition of forest fuel (birch leaves, spruce needles, kindling wood and mixed forest fuel) under conditions of exposure water aerosol and single water droplets, as well as water with specialized additives. We used typical model of fire source with fixed height $0.04 \mathrm{~m}$ and varied diameter $0.02-0.1 \mathrm{~m}$. Water spraying process, as well as interaction between water and forest fuel was registered using highspeed video camera (recording frequency $6 \cdot 10^{5} \mathrm{fps}$ ) and panoramic optical methods ("Particle Image Velocimetry", "Shadow Photography"). We established principles of water additions' influence on termination of combustion and thermal decomposition of fire source model.
\end{abstract}

\section{Introduction}

Forest fire fighting is an urgent problem for the entire world community. Especially it is necessary to distinguish brush fires, because the dry forest litter is often ignited. Huge areas of the forest burn down during brush fires $[1,2]$. The steady spread of ignition along the lower tiers of forest vegetation and litter is often the cause crown fire. Deceleration of the fire front and elimination of forest fires involves dropping the extinguishing liquid directly into the combustion zone [3-5]. The aviation park for firefighting in boreal zone often includes tankers, seaplanes and helicopters, equipped with special tanks for collecting, transporting and draining the water. Increasing the effectiveness of using such method is one of the urgent tasks. Additive component are often used in order to enhance fireextinguishing properties of water. Nowadays there is a large database of specialized additives to water. Such components can increase the viscosity of quenching liquids (fireretardant) or reduce her interracial tension (wetting agents). Also, it is important to analyze the influence of the forest fuel (FF) structure on the process under consideration. These reasons lead to experimental studies of the process of quenching model of fire source in laboratory conditions in order to justify the choice of a chemical reagent for fire extinguishing. Such study also will help show how wetting and fire retardant chemical compounds effect on suppression of FF thermal decomposition.

\footnotetext{
* Corresponding author: zhdanovaao@tpu.ru
} 
The aim of this work is an experimental study of the integral characteristics of flame burning suppression and model of fire source thermal decomposition with water, which contains specialized additives.

\section{Experimental setup and procedure}

Fig.1 shows the scheme of experimental setup used in carrying out researches. As the main recording equipment we chose a high-speed digital CMOS video camera Phantom V411 1 with a recording frequency is of $6 \cdot 10^{6} \mathrm{fps}$ and maximum resolution of $1280 \times 1280$ pixels), a high-speed (the minimum polling rate is $0.1 \mathrm{~s}$ ) analog input module "National Instruments NI 9216" 5 for temperature sensors connection, XA (K) thermoelectric converters 7; personal computer 8 , ViBRA HT 84RCE laboratory microbalance (with an accuracy of $10^{-5}$ g).

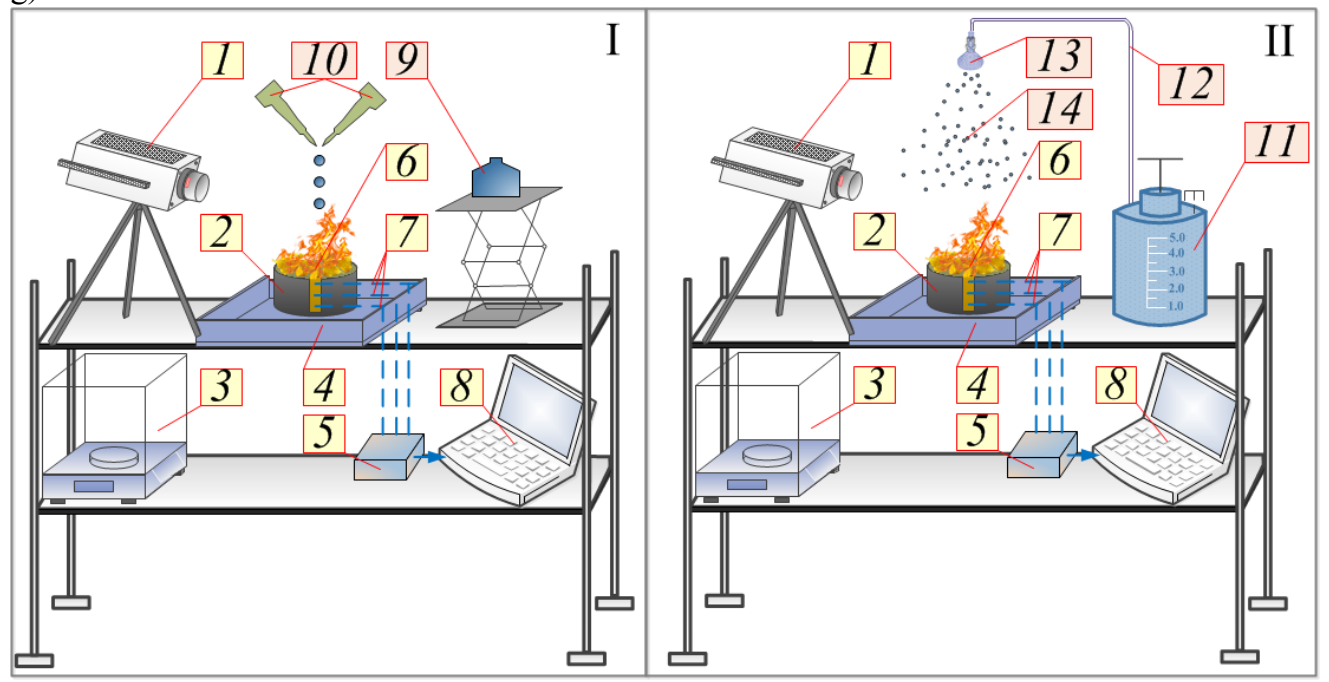

Fig. 1. A scheme of experimental setup: 1 - high-speed video camera; 2 - cylinder with a FF; $3-$ analytical microbalance; 4 - metal tray; 5 - high-speed analog input module; 6 - FF; 7 thermocouples; 8 -workstation (PC); 9 - quenching tank; 10 - single-channel dispencer; 11 - bulb with quenching liquid ; 12 - quenching liquid supply channel; 13 - spraying nozzle; 14 - liquid aerosol.

We used typical forest fuel, such as birch leaves, spruce needles, kindling wood and mixed $\mathrm{FF}$ (with mass ratio: $25 \%$ birch leaves, $15 \%$ spruce needles, $60 \%$ aspen branch) for our researches. The relative FF moisture in our experiments was 5-8 \% for birch leaves, 7$10 \%$ for spruce needles, $10-14 \%$ for aspen branch. We used hollow cylinders of corrugated aluminum to create model of fire sources. Cylinders had height $h_{\mathrm{f}}$ and diameter $d_{\mathrm{f}}$.

We picked distilled water (GOST 6709-72), water-based formulations with the "Progress" wetting agent addition and special-purpose foaming agents (type "AR") as quenching liquids. The relative mass concentration of the compositions used in the aqueous solution was $1 \%$. Quenching liquids were prepared directly in the vessel 11 , which was full of distilled water. The solution with the "Progress" wetter was mixed until the foam formed on the surface of the liquid. The wetting agent solubility was controlled visually. Similar actions were carried out for the preparation of a quenching liquid based on water and a foaming agent "AR".

Ignition of the model of fire source was carried out uniformly over the entire area of the open FF surface. We used three piezoelectric gas burners simultaneously for this purpose. 
The procedure for conducting the experiments included three stages. During the first stage of experiments the features and times of complete model of fire sources burn-up $\left(t_{\mathrm{b}}\right)$ for each FF were recorded. At the second stage of our experiments we registered the times of suppression FF thermal decomposition $\left(t_{\mathrm{e}(\mathrm{d})}\right)$ during successive feeding of single droplets of quenching liquid. The third stage was analogous to [6] and included determining the extinguishing times $\left(t_{\mathrm{e}(\mathrm{ae})}\right)$ of model of fire sources in the conditions of the liquid aerosol supply.

The first stage of experiments consisted of several operations. The model of fire source was ignited. We started the countdown on the electronic stopwatch. Three type-XA (K) needle thermocouples were placed on cylinder's symmetry axis (temperature measurement range $223-1473 \mathrm{~K}$, accuracy $\pm 3 \mathrm{~K}$, heat retention no more than $0.1 \mathrm{~s}$ ). The value $t_{\mathrm{b}}$ was registered. The choice of this value was determined by the corresponding limiting temperatures of the forest fuel thermal decomposition. The criterion for stable FF burning was the excess of the thermocouple readings above $370 \mathrm{~K}$ (FF thermal decomposition temperature).

At the second stage we determined the times of suppression of the FF thermal decomposition $t_{\mathrm{e}(\mathrm{d})}$ during successive delivery quenching liquid droplets. Quenching was carried out by successive feeding of single droplets with radii $R_{\mathrm{d}} \approx 1.5 \mathrm{~mm}$ (the drops' volume was $\left.V_{\mathrm{d}} \approx 15 \mu \mathrm{l}\right)$. Sequential droplet generation was realized using two electronic single-channel dispensers 10 Finnpipette Novus (the minimum and maximum withdrawable volumes are $10 \mu \mathrm{l}$ and $100 \mu \mathrm{l}$, the variation step is $0.1 \mu \mathrm{l}$ ). The frequency of generation is 1 drop per 2 seconds. The droplet delivery was realized until the model fire was completely suppressed. The conditions for suppressing the combustion were fixed by the results of the thermocouple readings. Afterward the obtained results were refined when analyzing the video of the quenching process from a high-speed video camera 1 .

The third stage of the experiments (quenching of the model of fire sources) included the liquid aerosol supply to the FF surface. The macroscopic principles of the interaction between water vapor and thermal decomposition products were recorded using optical methods of diagnostics ("Particle Image Velocimetry", "Shadow Photography", similar to $[6,7]$.) After 10-15 seconds (sufficient time to light the entire FF hinge), at the moment when the readings of the two upper thermocouples were higher than the thermal decomposition temperature $\left(T_{\mathrm{if}} \approx 370 \mathrm{~K}\right)$, the shut-off valve was opened and water from the tank 11 was supplied through the channel 12 to the inlet of the spraying nozzle 13 . The spraying continued until the full suppression of model of fire source combustion. The stopping point of combustion was fixed by the thermocouple readings 7 . The values $t_{\mathrm{e}(\mathrm{ae})}$ were recorded.

We conducted from 15 to 20 experiments for each model of fire source with corresponding FF. After that we chose the experimental values of $t_{\mathrm{b}}$ or $t_{\mathrm{e}(\mathrm{ae})}, t_{\mathrm{e}(\mathrm{d})}$, differed by less than $5 \%$ for identical experimental conditions. Amount of results excluded from consideration in this case did not exceed $10-15 \%$ of the total. The error in determining the values of $t_{\mathrm{b}}$ and $t_{\mathrm{e}}$ was due to the thermal delay time and was $1 \mathrm{~s}$.

\section{Results and discussion}

Conducted researches enable us to make the conclusion about efficiency of extinguishing by a liquid aerosol and single water droplets. The recorded termination times of the thermal decomposition reaction are much less than the burn-out times of models of fire source. In addition, the obtained experimental results (Fig. 2) for determining the time of the FF pyrolysis reaction suppression (for example for birch leaves) make it possible to conclude that foaming agents and wetting agents are need to added to the water. Fire-retardant (for example, a foaming agent of the "AR" type), chemical compositions allow increasing the 
quenching liquid viscosity, and, as a consequence, increasing the its fire-extinguishing properties. Adding the same surface-active additives (wetting agents, in particular, "Progress"), on the contrary, can significantly reduce the water surface tension, which contributes to a significant increase in its spreadability over the surface and promotes crushing into small droplets.

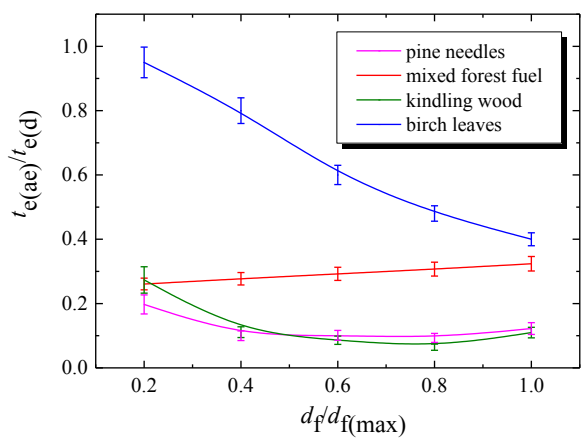

$a$
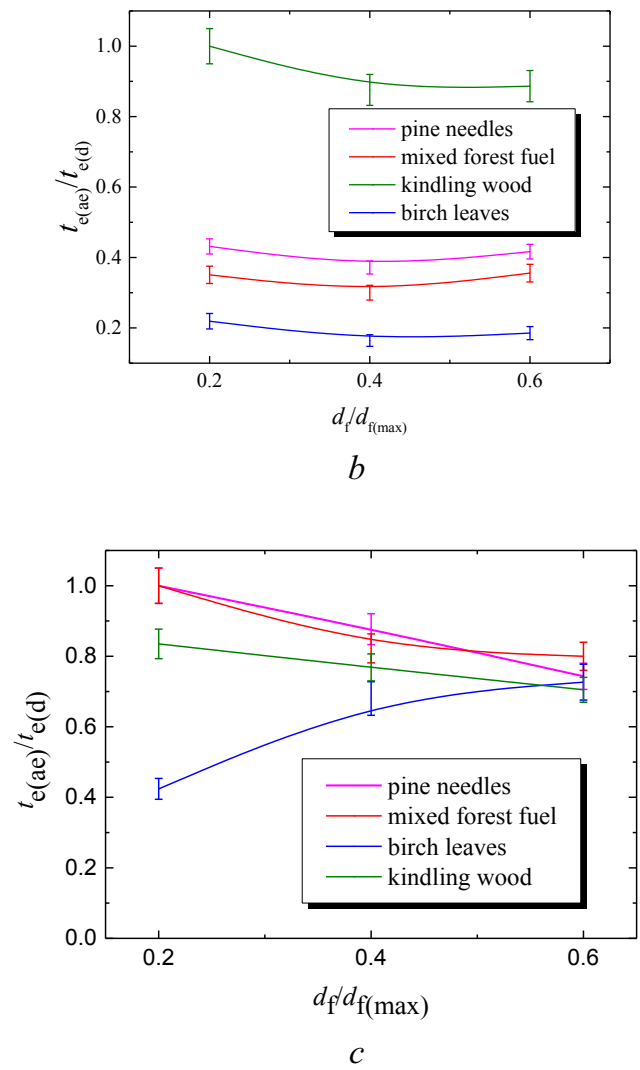

Fig. 2. Dependence $t_{\mathrm{e}(\mathrm{ae})} / t_{\mathrm{e}(\mathrm{d})}$ on $d_{\mathrm{f}} / d_{\mathrm{f}(\max )}$ for typical FF under the influence of liquid aerosol and single droplets: $a$-water, $b$-wetting agent "Progress", $c$ - foaming agent type "AR".

Moreover, chemical compounds added to water affects the extinguishing liquid evaporation completeness as it passes through flaming and flameless combustion zones 
(Fig. 2) [8]. The most typical mechanism for suppressing the reaction of FF destructiom is realized by increasing the quenching liquid surface tension. Droplets of a sprayed liquid, draining on the FF surface, form a liquid film and block the heated pyrolysis gas products output. When water was mixed with the appropriate chemical compounds, we observed foam formation, which led to the creation of a stable buffer zone between the heated FF pyrolysis products and the oxidizer.

\section{Conclusion}

As a result of the experimental studies, we established times of suppression of forest fuel thermal decomposition under the influence of water and its compounds. We established, how model of fire sources' transverse dimension effects on the process of extinguishing the ground cover. The performed experiments make it possible to draw a conclusion on the expediency of adding "AR" type foaming agents to water. Close values of the suppression the FF thermal decomposition reaction time during extinguishing with steam and droplets of quenching compositions based on a foaming agent are established.

Investigations of high-temperature evaporation of water droplets were carried out with the support of a grant from the President of the Russian Federation (MD-1221.2017.8). Experiments to determine the specific differences between the processes of thermal decomposition and combustion of various types of forest fuel were carried out within the framework of grant from the President of the Russian Federation (MK-1684.2017.8).

\section{References}

1. C. C. Remy, M. Lavoie, M. P. Girardin, H. Asselin, A. A. Ali, J. Biogeogr., 1 (2017)

2. A. O. Zhdanova, G. V. Kuznetsov, J. C. Legros, P. A. Strizhak, Thermal Science, 21, 6A, 2559 (2017), DOI: 10.2298/TSCI151006121Z

3. R. S. Volkov, A. O. Zhdanova, G. V. Kuznetsov, P. A. Strizhak, Tech. Phys., 60, 1443 (2015), DOI: 10.1134/S1063784215100291

4. D. Morvan, Fire Saf. J., 71, 34 (2015), DOI: 10.1016/j.firesaf.2014.11.012

5. O. P. Korobeinichev, A. G. Shmakov, V. M. Shvartsberg, A. A. Chernov, S. A. Yakimov, K. P. Koutsenogii, V. I. Makarov, Fire Saf. J., 51, 102 (2012), DOI: 10.1016/j.firesaf.2012.04.003

6. V. M. Gumerov, A. O. Zhdanova, M. M. Osmolovskaya, P. A. Strizhak, MATEC Web of Conferences 37, 01022 (2015), DOI: 10.1051/matecconf/20153701022

7. R. S. Volkov, O. V. Vysokomornaya, A. O. Zhdanova, P. A. Strizhak, EPJ Web of Conferences, 82, 01059, (2015), DOI: 10.1051/epjconf/20158201059

8. R. S. Volkov, A. O. Zhdanova, G. V. Kuznetsov, P. A. Strizhak, Thermal Engineering (English translation of Teploenergetika), 62, 586 (2015), Article number A008, DOI: $10.1134 /$ S0040601515080091 